\title{
Exhumaciones y memoria histórica en Castilla y León. El voluntariado memorialista ante la incomparecencia institucional
}

\author{
Exhumazioak eta memoria historikoa Gaztela eta Leonen. \\ Boluntario memorialistak erakundeen absentziaren aurrean \\ Exhumations and historic memory in Castilla y León. \\ The memorialist movement without institutional assistance
}

\author{
Pablo García Colmenares \\ Universidad de Valladolid \\ pablo.gcolmenares@uva.e
}

\begin{abstract}
Resumen
En las provincias que componen hoy Castilla y León el triunfo del golpe de estado de julio de 1936 se produjo de inmediato, y, en realidad, no se puede hablar de Guerra Civil y sí de represión institucional de los sublevados, que sembraron sus tierras de cientos de fosas comunes. En este siglo las asociaciones de esta región se han destacado por su labor para recuperar la memoria y los restos de las víctimas de la Guerra Civil, de ahí que sea el territorio español donde más exhumaciones se han realizado. Eso sí, una labor exclusiva del movimiento memorialista que ha realizado el trabajo con total ausencia institucional, aunque con los equipos arqueológicos y forenses más experimentados. De algún modo, ha sido una reivindicación de la que fuera "cuna del Alzamiento Nacional» a ser la "cuna» del movimiento memorialista nacional.
\end{abstract}

\section{Palabras clave}

Guerra Civil; represión; memoria histórica; exhumaciones; movimiento memorialista.

\section{Sumario}

1. AUSENCIA DE UNA JUSTICIA TRANSICIONAL Y UNA «COMISIÓN DE LA VERDAD» EN ESPAÑA. 2. UN DEBER DE MEMORIA DE LOS VALORES DEMOCRÁTICOS. LA MEMORIA HISTÓRICA DEMOCRÁTICA. 3. LAS EXHUMACIONES DE FOSAS COMUNES ENTRE 1970 Y 1982. 4. LA RECUPERACIÓN DE LA MEMORIA HISTÓRICA. LAS EXHUMACIONES COMO DISTINTIVO DE CASTILLA Y LEÓN EN EL SIGLO XXI. 4.1. Las exhumaciones entre el año 2000 y 2018. 4.2. Las exhumaciones desde el 2018. 5. LA MEMORIA HISTÓRICA EN LOS LIBROS DE TEXTO. UN VACÍO QUE DEBE LLENARSE CON CONCIENCIA HISTÓRICA. 6. CONCLUSIONES. BiBLIOGRAFÍA. 


\begin{abstract}
Laburpena. Gaztela eta Leongo probintzietan, 1936ko uztaileko estatu-kolpeak segituan lortu zuen garaipena, eta, egiari zor, ezin da esan han Gerra Zibila izan zenik, baina bai, ordea, matxinatuen errepresaliak, erakundeetatik bertatik ere eginak, eta ehunka hobi komunez josi zituztela hango lurrak. Mende honetan, Gaztela eta Leongo elkarteek lan nabarmena egin dute orduko memoria eta Gerra Zibilaren biktimen gorpuzkiak berreskuratzeko. Horregatik da Gaztela eta Leon exhumazio gehien egin den Espainiako lurraldea. Hori bai: mugimendu memorialistako jendeak bakarrik egin du lan eskerga hori, erakundeen erabateko absentziaz baina eskarmentu handieneko arkeologo eta forentseen laguntzaz. Nolabait ere, garai hartako "Altxamendu Nazionalaren sehaska» izatetik "Espainiako mugimendu memorialistaren sehaska» izatera pasatu dae.
\end{abstract}

Gako hitzak. Gerra Zibila; errepresioa; memoria historikoa; exhumazioak; mugimentu memorialista.

\begin{abstract}
In the provinces of Castilla y Leon the triumph of the coup d'état of July 1936 was immediate. In fact, it is not possible to talk about War Civil, but it is institutional repression of the rebels. They spread their lands with mass graves. In this century, the regional associations have distinguished them self in their work to recover memory and the remains of Civil War victims. In the Spanish territory has been where more exhumations have been carried out. In truth, one extensive work of the memorialist movement that has gathered support with experienced archaeological and forensic teams, but the work has been carried out without institutional assistance. In this way, the region that was the cradled of the National Uprising it, now has become cradle of the movement national memorialist.
\end{abstract}

Keywords. Civil War; repression; historical memory; exhumations; memorialist movement.

El territorio que conforma la comunidad de Castilla y León (CyL) fue uno de los primeros en caer en manos de los sublevados en julio de 1936, y se convirtió en la «cuna del Alzamiento» no solo por albergar las primeras instituciones de poder sino porque en ella se pondría en marcha el modelo fascista español. Y claro está, CyL fue el espacio donde se aplicó de forma sistemática la represión sobre todos los cuadros políticos, sociales, culturales e intelectuales que representaban a la II República democrática. Y eso que en este territorio no hubo Guerra Civil (GG), propiamente, salvo los frentes de batalla en los pasos de la cornisa cantábrica en el norte de Burgos-Vizcaya, Palencia-Santander, León-Asturias (hasta septiembre de 1937), y el frente de Guadarrama-Segovia-Madrid, además del sureste de Ávila-Madrid, que no pudo mantenerse más que unos meses. En puridad, pues, no hubo GC y apenas una resistencia testimonial de las autoridades gubernativas o municipales, en los edificios públicos de las capitales y en las Casas del Pueblo, que duraron unas horas, lo que tardan en ceder unas escopetas y pistolas repartidas apresuradamente y con poca munición ante una compañía militar con fusiles, ametralladoras y cañones. Se trataba de mostrar cómo era arrebatada la dignidad democrática por la fuerza de los rebeldes sublevados, pero estos no se iban a conformar con ocupar el poder, sino que había que eliminar todo vestigio del proceso democrático republicano y a ello se entregaron tanto los militares como los grupos paramilitares, dejando este amplio territorio lleno de cadáveres 
en cientos de fosas comunes que han llegado hasta el siglo XXI. Su objeto era evidente: que desaparecieran no solo los restos de las víctimas sino, también, su recuerdo y memoria y, con ello, el conocimiento histórico de lo sucedido.

Para el estudio del proceso golpista en esta región y su impacto represivo, existe ya amplia bibliografía desde la década de los noventa ${ }^{1}$, seguida en este siglo por las investigaciones de García Colmenares² ${ }^{2}$ Delgado y López ${ }^{3}$ y, a modo de síntesis, la última publicación de Berzal $^{4}$ que recoge lo esencial de la historiografía publicada en este territorio. Finalmente, debe destacarse el compendio de la actividad del movimiento memorialista regional en este siǵlo XXI, recogido en el número 18 de la revista Memòria antifranquista dedicado a $\mathrm{CyL}^{5}$. Con respecto al número de fosas comunes existentes en esta CCAA, aún hoy no tenemos los datos definitivos, como ocurre, también, en buena parte del resto de España. Sí tenemos recogida la información del número de fosas exhumadas desde finales de los años setenta, con escasos medios materiales y profesionales, y especialmente las exhumaciones realizadas en este siglo, siguiendo protocolos arqueológicos y forenses. Pero hoy muchas fosas han desaparecido por las actividades y construcciones viarias sobre ellas o su localización ha resultado fallida en los intentos realizados, en buena medida por la pérdida de los testimonios directos al fallecer ya los testigos que podían precisar la localización. El esfuerzo de la Oficina de Víctimas de la Guerra Civil, creada a raíz de la entrada en vigor de la llamada Ley de Memoria Histórica (MH) de 2007, ayudó a la confección del Mapa de Fosas de España del Ministerio de Justicia. Pero fue poco más que el inicio de un proceso que luego han seguido los equipos arqueológico-forenses, como el liderado por Francisco Etxeberria, desde el Instituto Aranzadi. Este ha ido precisando el mapa de fosas con la creación de fichas técnicas como ha expuesto en sus publicaciones desde 2012 .

Por otro lado, una parte significativa de las CCAA han respondido favorablemente a la demanda de la actual Secretaría de Estado de Memoria Democrática (MD) para la elaboración más detallada del mapa de fosas comunes de cada provincia de España, marcando su localización geográfica y estado actual: exhumada,

1 Blanco, 1995.

2 García Colmenares, 2007 y 2009.

3 Delgado y López, 2008, pp. 427-486.

4 Berzal, 2007 y 2020, pp. 409-436.

5 AA.VV., 2018. Los responsables de esta revista tienen, desde 2011, el objetivo de recoger y ofrecer en un número monográfico la situación historiográfica y memorialista de cada una de las regiones españolas: la Historia y memoria histórica de la Guerra Civil y represión posterior; así como las actuaciones en pro de la recuperación de la memoria histórica de las instituciones autonómicas y las asociaciones memorialistas. Hasta la fecha han publicado números referidos a nueve CCAA. 
destruida, no encontrada y la ficha con la información de su contenido en víctimas y breve comentario de su origen, etc. En el caso de CyL se ha iniciado desde el año 2019 la elaboración de este mapa recabando la información disponible en manos de las asociaciones memorialistas que han actuado en este territorio, por lo que en un tiempo corto debería estar disponible, tras la supervisión del arqueólogo Juan Montero de la Universidad de Burgóos. La evidencia, en todas las provincias, es que el número de fosas es muy superior a los datos que hasta ahora se han manejado a nivel institucional. Se podría aventurar que la información actual duplicará el número de fosas fijado oficialmente en 180 para las nueve provincias de $\mathrm{CyL}^{6}$. En esta lista aparecen las fosas exhumadas a finales de los años cincuenta para ser enviados los restos a rellenar los columbarios del Valle de los Caídos, nada menos que 71 de ellas. Así que 109 serían las fosas sobre las que se ha actuado desde la Transición, y sobre todo en el siǵlo XXI. No obstante, estos datos ya no se sostienen pues en CyL se han exhumado, desde el año 2000 hasta 2020, 233 fosas comunes, eso sin contar con las numerosas exhumaciones mal documentadas, llevadas a cabo en los años setenta y principios de los ochenta, como luego se verá. Por tanto, en una suma provisional, si a esta última cifra añadimos las trasladas al Valle de los Caídos, tendríamos 304 fosas, y si sumamos las decenas llevadas a cabo en el final del franquismo y la Transición ${ }^{7}$, estaríamos en más de 330 fosas exhumadas y quedarían de añadir las que no han sido intervenidas o localizadas, que son un número notable y que, como decía, en pocos meses podremos conocer.

Así pues, a la vista de la provisionalidad de la información del número de fosas comunes existentes en toda España y en particular en CyL, es evidente que en esta región el número es muy elevado y lo más llamativo es el esfuerzo recuperador llevado a cabo por el asociacionismo regional. Hay que destacar que en torno a 20 asociaciones han estado activas en este territorio, algunas de forma ininterrumpida durante estos últimos 20 años, con la firme voluntad de anteponer la búsqueda de los restos de las víctimas para recuperar, también, su memoria y responder a la demanda de los familiares que lo reclamaban como urgente, por obvias razones de no poder esperar más ${ }^{8}$. Pero la labor del movimiento me-

6 Según el mapa de fosas comunes del franquismo del Ministerio de Justicia, que no se ha renovado desde 2011, habría 48 en la provincia de Burgoos, 31 en la de León, 24 en las de Ávila y Palencia, otras 15 en la de Segovia, 13 en Valladolid y 8 en cada una de las provincias de Salamanca y Soria. https://15mpedia.orǵ/wiki/Lista_de_fosas_en_Castilla_y_Le\%C3\%B3n\#Fosas_en_Castilla_y_ Le.C3.B3n

7 Solo tenemos constancia precisa de las 14 exhumaciones llevadas a cabo en la provincia de Soria y al menos 6 en la de Palencia y alguna en Burǵos, pero no de las del resto del territorio.

8 Emilio Silva (2020) en su último libro recoge varios artículos sobre la labor de las asociaciones para la recuperación de la memoria histórica en estos 20 años de actividad. Destaca la labor realizada atendiendo a los miles de familiares para la localización de los restos de sus víctimas. 
morialista regional ha sido extraordinario en otros muchos aspectos que llevan aparejado el proceso de exhumación: investigación y publicaciones, excavación arqueológica y forense, identificación de los restos, homenaje y reconocimiento público en la localidad de procedencia de las víctimas, placas, panteones y memoriales locales y provinciales, ciclos de conferencias y debates, exposiciones, etc., con un notable impacto social a través de los medios de comunicación y en el conocimiento del pasado traumático para tantos familiares.

Hay muchos aspectos que preocupan al movimiento memorialista general, más en unas CCAA que otras, ya que algunas sí han implementado desde 2007 políticas de memoria histórica, mientras que en CyL no se ha hecho nada hasta el decreto de abril de 2018, de corto alcance, como se dirá. Me refiero a la fijación de hitos de la memoria en los lugares más sobresalientes de la represión franquista, como las fosas comunes o los lugares de confinamiento y presidio y, desde luegoo, la revisión de los libros de texto de la enseñanza obligatoria con la inclusión de la memoria histórica de las/os vencidos y la memoria democrática de las/os defensores de las libertades democráticas republicanas. Este tema preocupa especialmente a las asociaciones de $\mathrm{CyL}$, ya que no han tenido avances en estos dos años de reuniones mantenidas con las consejerías implicadas de la Junta de Castilla y León.

\section{Ausencia de una justicia transicional y una «comisión de la verdad» en España}

Es evidente que los grupos políticos antifranquistas en la Transición no tenían la fuerza necesaria para imponer una depuración de las fuerzas de orden público y la Justicia, lo que condicionó el proceso de transición política posterǵando los aspectos más comprometidos del pasado y la violencia cometida. La coyuntura internacional no favoreció la recuperación o debate sobre la violación de los derechos humanos en la década de los setenta. En cambio, una década después, con la tercera ola de democratización, los derechos humanos se han convertido en un aspecto básico. De ahí las diferencias entre la situación de los países del sur de Europa, como España, y de Latinoamérica9 .

Las dificultades para exiǵir responsabilidades cuando el poder judicial, la administración, el poder económico y, sobre todo, las fuerzas de orden público y el Ejército estaban en manos continuistas de la dictadura llevan a la oposición democrática a hacer amplias concesiones, entre ellas no mencionar la exigencia

9 Barahona, Aguilar y González, 2002, pp. 52-53; Ovejero, 2020, pp. 245-275. 
de responsabilidades ${ }^{10}$. Y así, las diversas normas, en los meses previos, hasta la Ley de Amnistía de 1977, fueron celebradas más por lo que suponían de libertad de los presos políticos, que por atender a la cargá de fondo que era que también amnistiaba a quienes habían practicado tortura contra los derechos humanos durante la dictadura. Y esas concesiones y renuncias iban a tener y han tenido graves consecuencias hasta hoy, por la dificultad para sacudirnos las secuelas del pacto no escrito de amnesia colectiva y de una política de desmemoria consensuada $^{11}$. Para autores como Vicens Navarro la dejación de la MH en manos del pensamiento conservador, en aras de la concordia, supone olvidos y renuncias al conocimiento que son imperdonables en una democracia que se precie.

La interpretación conservadora de nuestra historia -promovida durante los cuarenta años de dictadura- no fue cuestionada masiva y extensamente (a lo largo del territorio español y en todos los ámbitos educativos, incluyendo las escuelas) durante la democracia. De ahí que el silencio histórico de las izquierdas significó, en la práctica, la continuación y reproducción de tal versión conservadora de nuestra historia, lo cual ha sido facilitado por el gran dominio que las fuerzas conservadoras han tenido y continúan teniendo en los medios de información y persuasión de nuestro país, situación reforzada todavía más en los últimos siete años de gobiernos conservadores ${ }^{12}$.

Lo que algunos historiadores critican ${ }^{13}$ no es tanto que las circunstancias históricas hicieran imposible la revisión del pasado en la Transición, por la desigualdad de las fuerzas contendientes, sino que una vez implantada la democracia con las mayorías absolutas del PSOE se olvidara del pasado del partido, de sus militantes históricos y de las 120000 víctimas que estaban en fosas comunes en las cunetas de la infamia del territorio español. Una omisión consciente que por eso fue y es imperdonable. La falta de una justicia transicional nos hurtaba, también, la creación de una «comisión de la verdad» que, como en otros países, hubiese planteado como primera medida la recuperación de los restos de las víctimas exhumando las fosas comunes. Una rémora nacional mantenida durante décadas para escarnio de todos los demócratas de este país. Se nos hurtaba no solo el conocimiento de la represión franquista sino la propia memoria histórica democrática que nos había llevado hasta la España actual, renegando de nuestra memoria en aras de la supuesta concordia y conciliación que ocultaba el conocimiento histórico. Sobre este silencio y olvido de la MH durante la Transición

\footnotetext{
${ }_{10}$ Prada, 2010, pp. 34-35.

11 Cuesta, 2007, p. 87.

12 Vicenç Navarro, «Ideología y política en España», El País, 4 de febrero de 2004.

13 García Colmenares, 2021a.
} 
y las primeras décadas de la democracia en España, ya existe una amplia bibliografía que refuerza lo señalado. Del mismo modo, sobre el conocimiento de las no políticas de memoria estatal y la recuperación de la $\mathrm{MH}$, tan desigual, en cada una de las CCAA, puede verse García Colmenares ${ }^{14}$. Las situaciones que muestra el panorama nacional no son de recibo en un país democrático por la enorme desigualdad y reconocimiento que tienen las víctimas y sus familiares, en función del color político del Gobierno regional. Desde el modelo de Andalucía, con planes cuatrienales de actuación, aunque paralizados ahora con el Gobierno de coalición del PP, Ciudadanos y vox; o los de Cataluña, Navarra, País Vasco o Aragón. Y siguiendo la estela memorialista: Baleares, Comunidad Valenciana, La Rioja, Cantabria, Asturias, o Extremadura y Canarias que caminan en la misma dirección, o titubeantes como Castilla La Mancha; frente a las gobernadas por el PP, como Murcia y otras, donde las políticas de MH ni están ni se las espera, o han iniciado un proceso de retroceso como en Madrid.

\section{Un deber de memoria de los valores democráticos. La memoria histórica democrática}

El deber de memoria no es solo una responsabilidad que las generaciones sucesoras utilizamos en sentido moral, sino que trata de dar respuesta a una injusticia cometida, y, como señala Mate, es la memoria la que nos permite reparar la injusticia, porque sin memoria no hay justicia, porque el olvido destruye y disuelve la injusticia cometida. Y no lo hace como una rémora para mantenernos siempre en el pasado sin avanzar en el presente y futuro, al contrario, la memoria es la única que nos puede ayudar a superar y cerrar el pasado:

La memoria no sólo consiste en recordar hoy el vil asesinato del abuelo republicano, en la Guerra Civil, abandonado en algún muladar; para sacarle de esa ignominia y darle una sepultura digna. Eso sería una comprensión privada y moral. Es también algo más; es sobre todo algo mucho más que eso: es un acto político y epistémico. Político, en el sentido de que esa memoria del abuelo, muerto por republicano, cuestiona la legitimidad del franquismo construido sobre un golpe de Estado contra la República. Y es epistémico porque la mirada de la víctima ve algo sobre nuestra realidad que no alcanzaríamos sin ella. Tampoco es una operación restaurativa. No se trata de reproducir el pasado, sino de acabar con él. La memoria apunta al pasado de los fracasados, de los perdedores, de los que se han quedado en la cuneta del progreso; en una palabra, de las víctimas

${ }^{14}$ García Colmenares, 2021b, pp. 213-264. 
de la historia, y si se les recuerda es para acabar con esa lógica de la historia que sólo sabe caminar sobre ruinas y cadáveres. La memoria nos convoca para que esa historia acabe de una $v e z^{15}$.

Por eso, cuando se habla de memoria se debe precisar qué se entiende y pretende; que no es un mero sentimiento (evocación sentimental del pasado), ni un mero conocimiento (la información que proporcionan los testigos), sino algo más, un imperativo categórico que aúna experiencia con conocimiento. Ya que sin la memoria las generaciones siguientes no tendrían conocimiento de lo sucedido, como si la injusticia o la barbarie no hubieran tenido lugar. Y sin memoria no puede haber justicia, y en esta situación se podrá reparar lo reparable, como se ha hecho con alguna legislación referida a las víctimas de la represión franquista, reconociendo derechos laborales o jubilación y reparación moral de las sanciones. Pero cabe hacer justicia de lo irreparable más allá de las voces que piden pasar páǵina o echar la memoria al olvido. Hay que hacer memoria de lo irreparable:

La memoria abre expedientes que la ciencia da por archivados [...] La «ciencia histórica» tiene por objetivo contar los hechos si no como fueron al menos lo más parecido a cómo ocurrieron. Su afán explicativo no pretende hacer un juicio moral sobre lo sucedido. La memoria, sí. Para la memoria, en efecto, las injusticias no son desigualdades, por eso habla de víctimas y verdugos o de responsabilidad histórica. Tampoco se identifica con la «ciencia jurídica» especializada en identificar delitos, mientras que la memoria habla de culpas [...] La culpa es un concepto moral que liga [...] con el daño a la víctima [...] La culpa sobrevive al delito [...] aunque se haya cumplido el castigo previsto... Ni se identifica con la «ciencia política» cuya política de memoria poco tiene que ver con la memoria pública que aquí interesa. Aquella [...] está pensada en función de los ciudadanos presentes porque la política es de los vivos, mientras que la memoria pública está en función de los ausentes ${ }^{16}$.

Pero con respecto a la recuperación de la $\mathrm{MH}$, y especialmente a la $\mathrm{MD}$, algúnos autores son críticos con el «deber de memoria» como imperativo categórico que puede limitar el alcance de nuestra actuación a la reparación del trauma y el dolor sufrido por las víctimas. Sin despreciar esa actividad de las políticas públicas de memoria, hay que ir más allá para no perder de vista el objeto final que es resaltar la lucha y el sufrimiento de los antifranquistas y sus valores por recuperar o instaurar la democracia. Para Vinyes el principio que establece la memoria como un deber, como un imperativo moral, es rígido ante cualquier reasignación de la sociedad en cada momento. Pretende fijar la mirada más que en el dolor provocado

\footnotetext{
15 Mate, 2007b, p. 359

${ }^{16}$ Mate, 2013, p. 151.
} 
por la represión de la dictadura, en la transǵresión contra ella de los defensores de las ideas y valores democráticos. Ya que el dolor es una experiencia personal y colectiva, pero la transǵresión es un valor siempre y nos sirve como reclamo contra la injusticia. «Y me atrevería a decir que es el núcleo central, la masa crítica de la memoria democrática, y por tanto el capital transmisible en el tiempo» ${ }^{17}$. Para este autor, más que el dilema sobre el deber de memoria, que se contrapone al olvido y esteriliza a las instituciones para no hacer nada o bien poco, es más importante no perder de vista la obligación de las instituciones democráticas del Estado para explicar los «costes» de su implantación, como un bien conquistado mediante un esfuerzo conjunto desde todos los ámbitos sociales y políticos y desde la calle:

Es el reconocimiento de este patrimonio y la demanda de transmisión del mismo [...] lo que constituye la memoria democrática en un derecho civil [...] Y el deber político general de la Administración es garantizar a los ciudadanos el ejercicio de este derecho mediante una política pública de la memoria, no instaurando una memoria pública. La primera, la política pública, es garantista: protege un derecho y estimula su ejercicio. La segunda, la memoria pública, se construye en el debate político, social y cultural que produce la sociedad según cada coyuntura ${ }^{18}$.

Por eso, Vinyes entiende que el concepto de recuperar la memoria histórica no se refiere al conocimiento científico de nuestro pasado, que es cada vez mejor, sino a la rebelión contra la impunidad del relato fundacional construido de la implantación de nuestra democracia y Transición que han mantenido los gobiernos desde 1977. Lo que viene a demostrar que el conflicto real reside en la transmisión de la memoria democrática y su constante reasignación. Hoy es indefendible que el espíritu de la Transición fuera la reconciliación, cuando el auténtico espíritu era la conquista de la democracia. Así se entiende la incomodidad de los gobiernos que han ido seǵmentando todas las iniciativas, parcheando el procedimiento, sin tener una política pública coherente que tuviera un objetivo definido sobre cuáles son los elementos patrimoniales de la democracia y garantizar su transmisión. Un programa para preservar y socializar ese patrimonio material e inmaterial y actuaciones que estimulen la comprensión y uso de esos valores democráticos; y finalmente, un instrumento con normas, instituciones y recursos para realizarlo. Y es tajante con sus propuestas:

... el daño causado por la dictadura es irreparable. Nada, absolutamente nada puede reparar lo sucedido ni en la esfera individual ni en la colectiva, puesto que lo pasado ha marcado para siempre cualquiera de los niveles de la sociedad...

\footnotetext{
17 Vinyes, 2009, p. 25.

18 Vinyes, 2009, pp. 29-30.
} 
cuyas consecuencias ya expresó Primo Levi... La primera es que, ante lo irreparable, el perdón no tiene sentido. No lo tiene la demanda de disculpa por parte del Estado... No hay nada que perdonar. El daño causado por el golpe de Estado y por los cuarenta años de dictadura de un Estado que hizo de la violencia su valor principal y, por ello, su política permanente ha tenido unas consecuencias y un legado sencillamente imperdonables. Tan sólo debe ser explicado, admitido y asumido con todas las consecuencias que la sociedad determine desde la perspectiva democrática. Nada más ${ }^{19}$.

Y señala que la negativa del Estado a dar respuesta con políticas públicas de los valores en que se fundamenta la construcción de la democracia, frente a la dictadura franquista, ha dado lugar a disputas sobre las memorias del pasado y ha supuesto la resistencia a establecer una política pública sobre reparación y memoria, más de cuarenta años después de la instauración de la democracia.

\section{Las exhumaciones de fosas comunes entre 1970 y 1982}

Desde los inicios de la Transición política los familiares de las víctimas procuraron recuperar la dignidad de su identidad democrática reprimida, pero la Transición española no buscó sus antecedentes en la democracia republicana, lo que habría supuesto recuperar la memoria de la identidad de los represaliados. La Transición «echó al olvido» la identidad republicana temerosa de que hiciera sombra a la nueva monarquía ${ }^{20}$. Y eso que algunos familiares estaban haciendo exhumaciones de las fosas de sus víctimas sin apenas medios técnicos y, desde luegoo, sin apoyo arqueológico o forense. Hubo unos años de recuperación de memoria y apertura de fosas en toda España, pero duró poco tiempo por falta de apoyo oficial y por el temor generado tras el intento de golpe de Estado del 23F de 1981, que venía a ser una llamada de atención a los familiares de los vencidos, recordándoles que la democracia otorgada por los vencedores podía revertirse en cualquier momento. Las exhumaciones llevadas a cabo en los años setenta y principio de los ochenta tuvieron todo tipo de trabas administrativas por parte de los gobiernos civiles que enviaban a la Guardia Civil a recabar los permisos o autorizaciones. En muchos casos, en los que participaban los propios alcaldes y cientos de personas, se hacía la vista gorda, ya que los familiares presentaban la documentación requerida para la exhumación y traslado de restos cadavéricos,

\footnotetext{
19 Vinyes, 2009, p. 36.

${ }^{20}$ Castro, 2008; Hristova Dijkstra, 2007.
} 
que solo necesitaba del permiso de la Sanidad provincial ${ }^{21}$. Pero había que juntar una serie de circunstancias para llevar a cabo más de 100 exhumaciones que se hicieron en esos años en algunas provincias como en Extremadura, Navarra o Loǵroño, como plantea Paloma Aguilar ${ }^{22}$. Exhumaciones que se llevaron a cabo como si fueran actividades inoportunas para el delicado proceso que vivía el país, pues parecía que no podía soportar alteración alguna.

En CyL también hubo exhumaciones en varias provincias ${ }^{23}$, de las que existe poca información de sus resultados ya que no fueron hechas con procedimientos científicos. En Palencia tenemos ${ }^{24}$ constancia de las exhumaciones hechas en 1979 buscando a las víctimas del pueblo de Cevico de la Torre, en varias fosas comunes en las localidades del sur provincial (Villamuriel, Valdespina o Valoria la Buena [Va]). El número de restos recuperados superaba los cuarenta que fueron inhumados en un panteón levantado a costa de la principal inductora, Esperanza Pérez Zamora, con los demás familiares. Al año siguiente se recuperaba a otro grupo de víctimas de Dueñas enterradas en la cercana localidad de Cubillas de Santa Marta, para ser inhumadas en un panteón particular ${ }^{25}$. Y en 1982 la aǵrupación socialista de Palencia procedió a la exhumación de 12 jóvenes pertenecientes a las Juventudes Socialistas, en una fosa en Quintana del Puente, que fueron inhumados en un panteón en el cementerio de la ciudad, de donde provenían ${ }^{26}$. Similar actuación tuvo Javier Hernández, uno de los primeros alcaldes comunistas, en las elecciones de 1979, en Venta de Baños, encabezando la exhumación de una fosa en la cercana localidad de Villamediana e inhumados en la ciudad ferroviaria.

En el caso de la provincia de Soria, el libro de Herrero ${ }^{27}$ detalla los 93 lugares o parajes en los que se produjeron fusilamientos y enterramientos, algunos repetidos como la Caseta del Tío Romero, las Matas de Lubia, Llanos de Chavaler o Puente Ullán en Babuyas de Abajo. Y lo más llamativo es la relación de exhumaciones practicadas desde 1970 en la carretera de Bayubas a Tajueco con la recuperación de 10 cadáveres, o en Puente Ullán en noviembre de 1971 con la recuperación de 16 restos de otras tantas víctimas. Y así otras 14 exhumaciones en los años 1972 (2), 1977, 1979 (7) y 1981 (4), estas últimas después del $23 \mathrm{~F}$, lo que habla en favor de los familiares que no se echaron atrás ante las amenazas y miedos de otros. Y en la provincia de Burgos la primera exhumación la lideró

\footnotetext{
${ }^{21}$ Según el Decreto 2263/1974, de 20 de julio, BOE de 17 de agosto de 1974. Reglamento de Policía Sanitaria Mortuoria. En su art. ${ }^{\circ} 33$ señala solo la autorización de la Jefatura Provincial de Sanidad para su traslado y enterramiento.

22 Aguilar, 2018.

23 Etxeberria, 2012, p. 13.

${ }^{24}$ García Colmenares, 2011, pp. 439 y ss.

${ }^{25}$ García Colmenares, 2008, pp. 62-65.

${ }^{26}$ García Colmenares, 2011, pp. 182-184.

${ }_{27}$ Herrero, 1982, t. II, pp. 275 y ss.
} 
Blas Bombín, alcalde de Torresandino, cuando en 1979 exhumó, entre otros, los restos de su padre ${ }^{28}$. En todos los casos el esfuerzo fue de los familiares y el objetivo bien evidente: recuperar los restos de sus víctimas, ya que las instituciones y la mayoría de la población decían que no querían reabrir heridas o no era el momento de conocer nuestro pasado traumático. Pero es que, en general, no pudieron ser homenajeados debidamente más que en el funeral o en el traslado de los restos al cementerio para ser enterrados en algún panteón familiar ya existente, como en el caso de Dueñas o de las víctimas de Cevico de la Torre que fueron inhumados fuera de esa localidad en el cementerio de la capital. En este caso, al ser el panteón de nueva construcción, como el de los 12 jóvenes socialistas y los ferroviarios de Venta de Baños, sí se puso una placa alegórica.

Así pues, era evidente la demanda, casi obsesiva, o, mejor decir, traumática, de los familiares, que necesitaban acabar con el duelo de su tragedia familiar y mitigar su trauma antes de que llegara a la generación de los nietos. Los hijos/as querían cerrar el ciclo y no se lo permitieron, hasta fueron acusados de malos patriotas que anteponían sus intereses personales a algo tan elevado como la patria y la democracia. Como si ambos intereses fueran contradictorios, como dejaban ver los partidos y los colectivos antifranquistas que les dieron la espalda. En ningún momento hubo interés institucional en exhumar las fosas por sus muchas implicaciones y significados:

La apertura de las fosas ha permitido conocer la experiencia de la derrota, o de lo que podríamos denominar la «cultura de los vencidos». La importancia de ver los huesos convierte su realidad en incontestable [...]. Abrir una fosa implica abrir el pasado, con todo lo que esto supone de reencontrase con sentimientos de miedo, dolor, frustración y vergüenza [...]. Para las víctimas de la generación que vivió la guerra, la apertura de las fosas supone una irrupción de la memoria traumática, una renovación de la tragedia [...]. Pero la experiencia ha ido demostrando [que]... produce un verdadero alivio a estas personas [...]. Este dolor puede llegar a transformarse en un sentimiento de identidad orgullosa y reivindicativa ${ }^{29}$.

\section{La recuperación de la memoria histórica. Las exhumaciones como distintivo de Castilla y León en el siĝlo XXI}

Es la tercera generación, la de los nietos/as de las víctimas, la que recupera no solo a sus familiares sacándoles del olvido y silencio de la Transición, sino también la memoria de la II República ${ }^{30}$. Es evidente que los colectivos y organi-

\footnotetext{
${ }^{28}$ Castro, 2008, p. 264.

${ }^{29}$ Fernández de Mata, 2016, pp. 67-68.

${ }^{30}$ Cuesta, 2007, sp.
} 
zaciones de recuperación de la $\mathrm{MH}$, además de revisar la violencia de la guerra y posǵuerra, incorporando la memoria de los perdedores, están haciendo pedagogía democrática al debatir el trauma de nuestra GC, aún no asumido por la sociedad española y que afectó a cientos de miles de familias y sus descendientes durante tres generaciones. Un tema de enorme trascendencia y de total abandono en la democracia española como recoge en su último libro Ovejero ${ }^{31}$ partiendo de una revisión bibliográfica y comparativa con los países que han sufrido traumas similares.

Así, los vaticinios de que las asociaciones memorialistas iban a romper el consenso y la paz social, de que se iban a abrir viejas rencillas o hasta iniciar una nueva guerra en España, lejos de cumplirse, están logrando convencer a la mayoría de la población que entiende como justicia humanitaria la reparación de la memoria de las víctimas, y la licitud democrática de revisar nuestro pasado histórico más reciente. Abrir fosas, identificar sus restos y entregarlos a sus familiares para ser enterrados en lugar civil o saǵrado, no es, como dicen algunos, reabrir viejas heridas, sino cumplir un deber pendiente. Por eso entre las muchas actividades de las asociaciones, una de las más mediáticas es la apertura de fosas comunes por su evidente fuerza visual, testimonial y política. Las fosas comunes, «que son un testimonio dramático de las heridas de la memoria y de la historia [...], excavar las fosas significa, literalmente, excavar la memoria» ${ }^{32}$, están haciendo visible la espeluznante geografía de la represión franquista. Las exhumaciones del siǵlo XXI se han convertido en el elemento clave. Las fosas muestran la evidencia trágica y tanǵible de la barbarie, la represión, el silencio y olvido de su memoria. Son el testimonio dramático de las heridas de la memoria y de la Historia y el instrumento crucial de la comprensión de lo sucedido. Sería lo que Reyes Mate fija como el momento para la reconciliación de la memoria nacional, que permita a todas las instituciones que, antes, propugnaron el olvido, ahora, reparen su error. «Las víctimas han dejado de ser un efecto colateral para pasar a ser piedra angular de la política. Las víctimas al hacerse visibles, nos dicen sobre qué sufrimientos, injusticias o hipotecas está construido el presente, obligándonos a hacernos cargo» ${ }^{33}$.

La sociedad española tendrá que afrontar desde el Gobierno y el poder judicial la apertura de las fosas comunes, única manera de no alargar el proceso con los solo recursos de las asociaciones de voluntarios. Un movimiento asociativo que tiene su origen en alǵunas organizaciones nacidas desde mediados de la década de 1990 que luego tomarían impulso desde principio del siǵlo XXI con la

\footnotetext{
${ }^{31}$ Ovejero, 2020, pp. 215-245.

32 Fouce, 2007.

${ }^{33}$ Mate, 2007a, pp. 236-237.
} 
creación de las ARMH y el Foro por la Memoria que se implantan por casi todo el territorio nacional. La presencia de éstas en los listados de los primeros demandantes de ayudas del Estado en 2006 nos puede dar una idea aproximada de la tipología del asociacionismo en esa fecha, entre las que destacaban un buen número de asociaciones ubicadas en $\mathrm{CyL}$, como la ARMH de ámbito nacional, y las que actuaban en las provincias de Palencia y de Burgos: la Coordinadora provincial de Burgos, la del Penal de Burgos y de Valdenoceda o la de Miranda de Ebro. Además de Memoria y Justicia de Salamanca y las de Pozo Grajero y de Estudios y Exhumaciones de León. Todas ellas se llevaban un elevado porcentaje de las ayudas para exhumaciones en la región. Y se mantendría la tendencia creciente con más asociaciones en los años sucesivos, hasta el final del ciclo en 2012.

En el siǵlo XXI se inicia la fase científica con los protocolos para la recuperación de los restos de las víctimas de la GC en España, y es en esta región castellano-leonesa donde se fija su arranque con la apertura de la fosa de los «Trece de Priaranza del Bierzo» en el año 2000, iniciada por Emilio Silva y otros familiares, lo que supone el origen de la ARMH en España y «cuna» del movimiento memorialista actual ${ }^{34}$. Aunque ya había habido algunos precedentes con los restos exhumados de la Casa de Campo de Madrid y analizados por forenses de la Escuela de Medicina Leǵal de la Universidad Complutense en 1985; o los restos exhumados por el Grupo de Rescate en Montaña de la Guardia Civil y analizados en el Instituto Nacional de Toxicología de los 13 individuos recogidos en noviembre de 1998 en el Pozo Grajero, en el límite de León y Asturias, como recogen Etxeberria y Solés ${ }^{35}$. En esta fase se destaca la importancia del trabajo interdisciplinar que se produce en torno a la exhumación de una fosa, desde la investigación histórica hasta el trabajo arqueológico, forense físico y funerario, antropológico, psicológico, escultórico-artístico, etc., que cada vez aporta más información al conocimiento de la violencia ejercida sobre las víctimas desde su detención hasta el asesinato o fusilamiento, como recoge García-Rubio para el caso de las exhumaciones llevadas a cabo en el antiguo cementerio de la ciudad de Palencia, donde se han exhumado 114 cuerpos de los quinientos enterrados ${ }^{36}$.

\subsection{Las exhumaciones entre el año 2000 y 2018}

Las asociaciones en CyL fueron surǵiendo desde los primeros años del siglo XXI, siguiendo la estela de la ARMH y del Foro por la Memoria, y pronto sintieron la necesidad de buscar fórmulas de colaboración tanto a nivel nacional, a

\footnotetext{
${ }^{34}$ Silva y Macías, 2003.

35 Etxeberria y Solé, 2019, pp. 407-414.

${ }^{36}$ García-Rubio, 2019, p. 40.
} 
cuyas convocatorias asistieron representaciones, así como a las reuniones regionales para tratar de crear una coordinadora, que por falta de recursos humanos y materiales no se consolidó, aunque sí consiguieron constituirla en un primer momento para la Reivindicación de la MH en CyL, el 27 de junio de 2004, en una reunión celebrada en Valladolid con presencia de asociaciones de siete de las nueve provincias. Se hizo la constitución oficialmente el 9 de octubre de ese año, con una presentación pública con los objetivos recogidos en un «Decálogo contra el Olvido» que resumía las principales demandas del asociacionismo español. Meses después, el 23 de noviembre, se conseguía una reunión con el portavoz del PP en las Cortes autonómicas, en las que tenía mayoría absoluta, para recabar medidas de apoyo institucional ${ }^{37}$. Pero no hubo ningún interés del Gobierno regional. Tendrían que pasar catorce años hasta que los mismos protagonistas nos viéramos, otra vez, ante el primer decreto de las Cortes, de 12 abril de 2018, que parecía el inicio del proceso de recuperación de la MH, ya que debería haber iniciado el camino hacia una ley de $\mathrm{MH}$, pero que tampoco iba a tener mucho desarrollo, como se verá.

$\mathrm{El}$ asociacionismo de este territorio mantiene una elevada actividad investigadora en las exhumaciones de fosas comunes, en la realización de actos públicos de homenaje a las víctimas, así como la realización de monumentos en algunas capitales y en numerosos pueblos. No en vano, son las provincias que más exhumaciones han realizado en España. Desde el año 2000 a 2018: «se han exhumado 215 fosas comunes en CyL con el rescate de restos de 1869 víctimas» ${ }^{38}$. Datos que ha actualizado el mismo equipo Aranzadi que ha contabilizado 233 fosas y 1936 víctimas recuperadas ${ }^{39}$, destacando las provincias de Burgóos o León, que con varias exhumaciones en el mismo paraje y sin contar las catas fallidas superan las 80 intervenciones en cada provincia, aunque es Burgos donde las fosas eran más grandes con cerca de 950 víctimas recuperadas. El número de fosas exhumadas supera la treintena en provincias como Palencia o Valladolid, aunque la exhumación de las fosas del cementerio de las dos ciudades ha aumentado notablemente los datos de la región. En el caso de Valladolid la exhumación de 6 fosas en el cementerio de la capital, en los años 2016 y 2017, agregó 247 cuerpos de víctimas recuperadas y el memorial levantado e inaugurado en febrero de 2020 , en recuerdo-homenaje a las más de 2650 víctimas de toda la provincia. En las demás provincias, como recoge la bibliografía citada, hay decenas de exhumaciones en este periodo, fruto del intenso trabajo del asociacionismo regional.

\footnotetext{
${ }^{37}$ García Colmenares, 2005, pp. 172-173.

${ }^{38}$ Etxeberria, 2018, p. 14. En el listado se presenta la identificación del municipio, lugar, arqueólogo/a y número de víctimas recuperadas.

${ }^{39}$ Herrasti, 2020, p. 39.
} 
Para ponderar su esfuerzo comparado con el resto del territorio nacional el libro de las historiadoras Barranquero y Prieto $^{40}$ nos da un amplio comentario de las principales exhumaciones realizadas en la región; de ahí el interés por conocer los resultados de la iniciativa, en marcha, del Consejo Asesor de MH de la Junta de CyL, que debe remitir a la Secretaría de Estado de MD el mapa de fosas existentes en las provincias de la región. Para ello se ha financiado un proyecto con la Universidad de Burgóos dirigido por el antropólogo Fernández de Mata y el arqueólogo Juan Montero que nos dará información más precisa de las fosas de cada una de las nueve provincias.

\subsection{Las exhumaciones desde el 2018}

El RD 9/2018, de 12 de abril de 2018, de la Junta de CyL contaba con la aquiescencia de la mayor parte del asociacionismo al que reconocía su labor y la deuda contraída con las víctimas y sus familiares. Asimismo, pautó el inicio a las subvenciones para la confección de un mapa de fosas regional y para las exhumaciones, análisis genético y actos de inhumación. Y, desde luego, como aspecto notable se creaba un consejo técnico y otro asesor para hacer propuestas a la Junta regional, aunque apenas ha conseguido avanzar algo más que en el tema de las subvenciones para exhumaciones.

La ARMH de ámbito nacional ha seguido haciendo exhumaciones en este último periodo con financiación propia, muy crítica con las propuestas del gobierno regional, abriendo una fosa en Boadilla (Salamanca) en agosto de 2018 con 4 víctimas e interviniendo en varias fosas en Santa Lucía de Gordón (León) en busca de 11 víctimas. En octubre de ese año exhumaba tres víctimas en dos fosas en Casillas y Santa $\mathrm{M}^{\mathrm{a}}$ de Tiétar (Ávila) y, al año siguiente, en el cementerio de León los restos de la maestra Genara Fernández García, la «Pasionaria de Omaña», a la que inhumó con un homenaje en su localidad natal en agosto de 2020. Y este mismo año abría otra fosa con una víctima de la localidad de Los Crémenes, y en septiembre localizaban en el cementerio de El Espinar (Segovia) las fosas con los restos de, al menos, 10 milicianos.

Otra activa asociación es la ARMH de Valladolid que está embarcada en un nuevo proyecto, tan complejo como es la exhumación en las bodegá de los «Alfredos», en Medina del Campo, iniciada el año 2019 y continuada en un pozo de la misma propiedad en el verano de 2020. Esperan hallar 42 cuerpos de otras tantas víctimas de la comarca. Por su parte, la ARMH de Miranda de Ebro preparó con detalle la intervención en la llamada «Fosa de las Mujeres» en la que podía haber

${ }^{40}$ Barranquero y Prieto, 2018, pp. 99-114. 
un número de entre 9 y 20 cuerpos. El trabajo de búsqueda, bajo la dirección del Instituto Aranzadi, resultaría infructuoso por las evidencias de haber sido exhumadas al final del franquismo con el ocultamiento del destino de los restos. Mejores resultados tendrían las actuaciones de la Coordinadora provincial de Burgoos con la localización de la fosa de 7 víctimas en la Peredeja, en Ibeas de Juarros, en el verano de 2019, mientras que en octubre no pudieron encontrar la fosa del maestro Hermógenes Gallo en el término de Zurita. Sí lo pudieron hacer los familiares de las 4 víctimas recuperadas en dos fosas en Riba de Escalote (Soria), en septiembre de 2019, exhumación organizada por la asociación soriana Recuerdo y Dignidad, otra activa y única asociación española que ha conseguido la intervención judicial en dos exhumaciones, aunque como en el resto del país se hayan archivado por la presión de la Fiscalía que no atiende las razones internacionales de imprescriptibilidad de los crímenes contra la humanidad. Un tema que todo el movimiento memorialista nacional no ha dejado de demandar.

A menor escala, en hallazgos recientes, otras asociaciones como la ARMH de Palencia tenía resultados fallidos en la localización de tres fosas: dos en Quintana del Puente que debían albergar los restos de dos maestras, entre otros cuerpos, y otra en Villaconancio con los restos de 8 vecinos de una localidad cercana a Antigüedad, pero que gracias al trabajo del equipo Aranzadi hemos conseguido resolver al testar los datos de $\mathrm{ADN}$ de los familiares con los restos recuperados de otra fosa de la localidad de Baltanás. También cabe mencionar el caso de la asociación salmantina, Verdad y Justicia, que sigue trabajando en la zona de Ciudad Rodrigo, en la fosa del Valle del Lagar. Del mismo modo la iniciativa particular de los nietos de las víctimas ha conseguido se inicie el proceso de exhumación de una fosa en los terrenos de la Cartuja de Miraflores, en la capital burgalesa que, como muchas iniciativas señaladas, cuenta con equipos del Instituto Aranzadi ${ }^{41}$ o, en otros casos, con arqueólogos regionales, tan implicados personal y profesionalmente como Julio del Olmo o Juan Montero, entre otros.

Como evidente conclusión se puede deducir que el movimiento memorialista de esta región ha hecho un esfuerzo extraordinario desde el primer momento. Y lo sobresaliente es que siempre ha sido soportando los concursos competitivos públicos del Ministerio de la Presidencia, entre 2006 y 2012, y de la Consejería respectiva de la Junta de CyL desde el verano de 2018. Se puede decir que ha sido una labor del asociacionismo ante la incomparecencia de las instituciones en tantos y tantos aspectos, como recoge Emilio Silva en los más de cuarenta artículos publicados desde el año $2000^{42}$. En buena parte de ellos, desǵrana cómo las élites

\footnotetext{
${ }^{41}$ En esta región son bien conocidos y apreciados/as, los citados/as Francisco Exteberria, Lourdes Herrasti y Almudena García Rubio o Jimi Jiménez, entre otros.

42 Silva, 2020.
} 
de la Transición y democracia hicieron oídos sordos al rumor y las demandas de los familiares al Gobierno. Las asociaciones han actuado como subcontratas de la administración, ya que esta comunidad parece estar condenada a que le impongan la creación de un Instituto de la MHD bajo una ley nacional, pero no regional como el resto del país. Es la cara y la cruz de esta CCAA.

Pero, a pesar de su enorme dedicación exhumadora, esta no ha sido la principal actividad memorialista regional de las cerca de 20 agrupaciones que han estado activas en múltiples homenajes, ciclos de conferencias anuales y periódicos, actuaciones artísticas varias, levantamiento de memoriales con los nombres de las víctimas, placas y esculturas de hitos de la memoria, debates y publicaciones y hasta páginas web permanentes. No es fácil resumir los cientos de actuaciones de cada una de ellas en estos 20 años.

\section{La memoria histórica en los libros de texto. Un vacío que debe llenarse con conciencia histórica}

La actividad de los cientos de asociaciones existentes en España es y ha sido de extraordinaria importancia para el conocimiento y la difusión de la $\mathrm{MH}$ al realizar miles de actos culturales para el conocimiento de la Historia y de las víctimas, pasando por la recuperación de los restos cadavéricos de miles de asesinados en fosas comunes. Pero nos falta lo que podríamos denominar la prueba del éxito o fracaso de todas estas iniciativas que estriba en comprobar su impacto en la ciudadanía no solo a través de los medios de comunicación y redes sociales, como recoge el equipo investigador coordinado por Matilde Eiroa. Este grupo de investigación destaca la importancia de la información que vierten en la Red las diversas asociaciones de $\mathrm{MH}$, a modo «de gran repositorio de fuentes», con el ánimo de difundir y llegar a un mayor número de personas; aunque sean «un campo insuficiente para reunir las piezas necesarias de una narrativa histórica ${ }^{43}$; pero, como bien dice:

El movimiento memorial, por tanto, constituye un fenómeno multidimensional que ha encontrado en la Red un camino eficaz para su propagación y actividades. Su contribución ha sido fundamental en la recuperación de una memoria sobre un pasado traumático que está devolviendo la dignidad a miles de ciudadanos sin revancha ni deseo de venganza. Más bien están aportando propuestas para cerrar esta historia e incorporarla al discurso histórico oficial... Y construir una memoria nacional democrática, dando por finalizada una etapa caracterizada por una memoria fracturada. (p. 88)

\footnotetext{
${ }^{43}$ Eiroa San Francisco, 2018b, p. 80.
} 
De ahí que el aspecto ineludible sea su reflejo en los libros de texto escolares en los niveles obligatorios. Sin lugar a dudas este es un tema de notable interés científico y social para calibrar el verdadero alcance del esfuerzo de las asociaciones memorialistas. Es el mejor barómetro del grado de implantación de la MH, ya que a través de los textos escolares podemos conocer la revisión historiográfica que ya ha sido asumida por los centros universitarios, pero que tarda en llegar a los textos escolares.

Además, la historiografía actual asume el valor de la memoria tal y como la defiende Raimundo Cuesta ${ }^{44}$, que la entiende integrada de tal forma en la historia reciente que esta ya sea incompresible sin aquella, de ahí que abogue por definir «una historia con memoria». Pero no se trata solo de convertir a la memoria en un objeto de estudio, sino, también, concebirla como un método crítico de aproximación a la realidad, como método de indagación:

[...] que rescata el pasado ausente, el pasado ignorado de los vencidos, de modo que el pasado deja de ser un depósito inerte de experiencias y hechos y se convierte en un objeto de confrontación dialéctica con el presente [...] (para evitar que) $[. .$.$] bajo las apariencias del escaparate de la idea de progreso, se produzca$ el olvido de que hemos olvidado [...]. De la dimensión de la historia con memoria que defendemos se desprende el valor educativo inherente a un cierto imperativo o deber de recordar determinados momentos y situaciones del pasado ${ }^{45}$.

Supone educar contra la barbarie y que el saber histórico no es solo asunto de historiadores o, dicho de otra forma, es tan importante que no puede estar solo en manos de los historiadores. De ahí el concepto de uso público de la Historia con la idea de que el saber histórico tiene también una dimensión social y pública en la formación de la identidad democrática de los ciudadanos. La Historia al debatir las relaciones entre el pasado y el presente se ha convertido en un interés común por lo que ha pasado a ser de interés y opinión pública. Pero también al ser la memoria un método de investigación para conocer, interpretar y valorar el uso de la Historia en el aula, debe ser redimensionado no solo por el deber de memoria, sino porque la memoria puede tener una dimensión histórica, porque el pasado es algo que construimos cada vez que lo evocamos desde el presente.

La Historia hoy y su enseñanza están dando un giro radical con la incorporación de la memoria como conocimiento y como metodología crítica de análisis al dar voz a los que fueron silenciados a lo larǵo de ella por lo que, cada vez más, caminamos hacia una «Historia con memoria». Si tradicionalmente la Historia como narración hacía una selección de qué era historiable y por tanto aparecía

${ }_{44}$ Cuesta, 2011, p. 16.

${ }^{45}$ Cuesta, 2011, p. 19. 
en los libros dejando en la penumbra o en el olvido otros hechos, el uso de la memoria puede contribuir a hacer justicia con los olvidados en un nuevo relato histórico del pasado. La experiencia llevada a cabo en algunos centros de Secundaria tiene un referente en el IES Fray Luis de León de Salamanca, donde se ha llevado a cabo un proyecto -desde el curso 2003-2004- coordinado por Cuesta Fernández, como resume Molpeceres ${ }^{46}$.

Esta forma de hacer historia del presente permite reabrir heridas cerradas en falso o devolver la voz a los/as acalladas por la historiografía tradicional de los vencedores. Hoy, la historiografía pone su relato al servicio de la justicia y reparación de las víctimas, los silenciados y los olvidados. Y no se trata ya de estudiar o conocer la Historia para intentar que no se repita, sino de tomar las riendas del relato del pasado ya que somos responsables y resultado de ese proceso. Interesa no sólo el conocimiento de los hechos del qué sino del cómo y por qué sucedieron de esa manera, a modo de reflexión crítica desde la memoria de las víctimas. En esta línea de investigación y de presentación de resultados es en la que trabaja el equipo de profesores de la Universidad de León diriǵido por Díez Gutiérrez, que presenta uno de los mayores esfuerzos de síntesis del estado actual de los libros de texto escolares en el tratamiento de la memoria histórica ${ }^{47}$. Realizaron 610 entrevistas a profesoras y profesores de Historia y analizaron más de 20 libros de texto de 10 editoriales distintas con especial atención a los de cuarto de la ESO y segundo de Bachillerato, detectando notables diferencias entre ellos y deficiencias generales con respecto al nivel de profundización, al tratamiento de los temas como la represión franquista y las fosas comunes, la incautación de los bienes de las personas detenidas o asesinadas, la intervención decisiva de la Iǵlesia católica, así como el propio espacio dedicado al periodo histórico que va desde la II República hasta la Transición. Del mismo modo, la equidistancia en el tratamiento de la violencia o las causas del golpe de Estado, o la lucha del maquis y, cómo no, la MH que no se trata en los libros de texto, a pesar de que las directrices y objetivos de la normativa educativa nacional sí lo señalan.

El equipo de investigación de la Universidad de León publicó sus conclusiones con el título La Memoria Histórica en los libros de texto que puede consultarse en la web y que presenta los resultados de su investigación desde un análisis crítico de los contenidos de los libros de texto, cuantificando los aspectos formales, tratamiento y valoración de los temas y los aspectos cualitativos como la interpretación, ideologías subyacentes, opiniones sin contraste científico, etc. ${ }^{48}$ Los resultados de esta sólida y básica información se habían convertido durante

\footnotetext{
${ }^{46}$ Molpeceres, 2011.

${ }^{47}$ Disponible en PDF en la web Foro por la Memoria León: https://foromemorialeon.wordpress.com

48 Díez Gutiérrez, 2012.
} 
el proceso en la base informativa para proponer unidades didácticas adecuadas, introduciendo los conceptos de MH. Así, publicaron Unidades didácticas para la Recuperación de la Memoria Histórica ${ }^{49}$ dirigidas a $2^{\circ}$ de Bachillerato, en las que se planteaban tres unidades: «La causa republicana», "La represión franquista» $\mathrm{y}$ «La lucha antifranquista». Y lo hacían con un amplio esquema para dar cabida a todos los temas que la historiografía había asumido como conocimiento científico contrastado y documentado. Por otra parte, lo novedoso es que presentan el material en formato libro de texto, similar a los mejor diseñados desde la pedagogía y la didáctica científicas, adaptado a facilitar la mejor y más profunda aprehensión de la Historia y la MH para los estudiantes de las distintas etapas escolares, bajo metodologías activas. ${ }^{50}$ Recientemente, Enrique Díez ha revisado sus análisis con la continuación de sus indagaciones y los aportes de otros trabajos de investigación que refuerzan sus planteamientos previos, constatando el escaso avance en la incorporación de la MHD en los libros de texto escolares. Además, ha dado un paso más anunciando la edición, en papel, de las unidades didácticas elaboradas y adaptadas a un formato digital interactivo ${ }^{51}$.

Este era el bagaje de los representantes de las asociaciones memorialistas que acudieron a la convocatoria del consejero de la Presidencia de la Junta de CyL los días 24 de enero y 9 de febrero de $2018^{52}$, en las que se anunció la inminente publicación de un decreto de la memoria histórica y democrática de CyL. En esas

${ }^{49}$ Díez Gutiérrez y Rodríguez González, 2009. Ver el texto completo en el enlace: https://foromemorialeon.wordpress.com/2009/02/01/unidades-didacticas-para-la-recuperacion-de-la-memoriahistorica/

${ }^{50}$ Así, todas estas unidades didácticas parten de un mapa conceptual a modo de esquema visual de los temas y las relaciones de causa y efecto entre ellos para que el docente y el alumnado puedan tenerlo como referencia permanente. Un título bien definido; unos objetivos claros y sencillos que marcan las competencias que deben lograrse en el alumnado; algunos aspectos que se destacan con colores distintos; contenidos adecuados sencillos y rigurosos del tema; imágenes e ilustraciones que sitúan al estudiante en el periodo; gráficos, esquemas; mapas, cronologías que sirven de apoyo; documentos de la época; biografías breves de personalidades relevantes; pies de foto destacados y esclarecedores; una bibliografía básica y de fácil acceso con obras literarias, películas y documentales, así como páginas web para el uso en el aula o de refuerzo formativo; una relación de actividades para profundizar en la comprensión y otra novedad, la inclusión de testimonios y relatos resumidos de los testigos y familiares de víctimas, etc. Sin hablar de la relación de competencias que se persigue, del tipo de contenidos conceptuales, procedimentales o actitudinales; o de la metodología activa y de los temas transversales, como educación para la convivencia, para la paz y los derechos humanos y para la igualdad entre hombres y mujeres, por lo que el recurso al género como herramienta de trabajo es imprescindible. O la atención a la diversidad y a los criterios de evaluación.

51 Díez Gutiérrez, 2020, p. 151. Ver http://memoriahistoria.unileon.es

${ }^{52} \mathrm{Al}$ menos hubo representación de las asociaciones siguientes: «Pozo Grajero», Miranda de Ebro, Aranda de Duero, provincia de Burgos, Valladolid, Soria, Palencia y la ARMH nacional (Ponferrada) y Memoria y Justicia de Salamanca. 
reuniones desde la consejería se les pedía su opinión y propuestas para tenerlas en cuenta, lo que los representantes del asociacionismo memorialista escucharon con interés. En todos los casos, además de ponderar el deseo de recibir ayudas para seguir con las exhumaciones pendientes, manifestaron que llevados ya 18 años de trayectoria era el momento de iniciar, a la vez, la segunda fase memorialista que es la difusión y la fijación del conocimiento en la enseñanza obligatoria. En definitiva se demandó, entre otras cosas, la elaboración de material didáctico que la Consejería de Educación hiciera suyo y lo distribuyese para incluirlo en los textos escolares desde Primaria a Bachillerato. Propuesta que fue aceptada en el artículo 11 del Decreto de Memoria Histórica y Democrática de Castilla y León ${ }^{53}$, de abril de 2018. Para desarrollar este objetivo se creó una comisión dentro del Consejo Asesor de MH nacido en el mismo decreto, que estaba formada por los representantes del movimiento memorialista y los profesores universitarios representantes de la Universidad de Burgos, Salamanca y quien subscribe como miembro de la Universidad de Valladolid y representante del movimiento memorialista que, además, actuaba como coordinador del informe que se presentó en diciembre de 2018. La propuesta estaba elaborada y consensuada con los profesores de la Universidad de León: Enrique Díez Gutiérrez y Javier González, que estaban dispuestos a crear un grupo de trabajo -en el que se incorporarían representantes del movimiento memorialista- para elaborar las unidades didácticas de acuerdo con los parámetros que indica el currículum de la normativa estatal y la regional de $2015^{54}$.

La propuesta-informe fue presentada y defendida en la reunión mantenida con la Dirección General de Planificación Educativa (Consejería de Educación) el día 29 de enero de 2019, que no la tuvo, siquiera, en consideración, haciendo, por el contrario, un planteamiento tan poco riguroso como que los técnicos de la Consejería y los miembros de la propia comisión podrían elaborar las unidades didácticas. Y ahí se ha acabado el recorrido de esta iniciativa, poniendo de manifiesto una nueva incomparecencia de la institución responsable de la enseñanza de la CCAA. Se podría añadir, como antes señalaba, que el mismo escaso recorrido tuvo la otra comisión surgida del mismo seno y con similares protagonistas, coordinados por la profesora Eugenia Torijano de la Universidad de Salamanca, que

${ }^{53}$ Decreto 9/2018, de 12 de abril, de la Memoria Histórica y Democrática de Castilla y León. BOCYL, núm. 73 del 16 de abril de 2018.

${ }^{54}$ Real Decreto 1105/2014, de 26 de diciembre, por el que se establece el currículo básico de la Enseñanza Secundaria Obligatoria y del Bachillerato. BOE de 3 de enero de 2015. Y Orden EDU/362/2015, de 4 de mayo, por la que se establece el currículo y se regula la implantación, evaluación y desarrollo de la educación Secundaria obligatoria en la comunidad de Castilla y León. BOCYL de 8 de mayo de 2015. Y Orden EDU//363/2015, de 4 de mayo, por la que se establece el currículo y se regula la implantación, evaluación y desarrollo del Bachillerato en la Comunidad de Castilla y León. 
elaboró un informe que contemplaba los apartados básicos de la futura y necesaria ley de memoria histórica de CyL, tras el estudio comparativo de la normativa de las diversas CCAA del país.

\section{Conclusiones}

Es más que evidente el notable esfuerzo llevado a cabo por el asociacionismo de CyL en la RMH, de ahí que el subtítulo de este artículo sea manifiesto: la incomparecencia institucional en la recuperación de la $\mathrm{MH}$, que contrasta con la fuerza del movimiento memorialista, que, después de dos décadas remando solo, empieza a acusar el esfuerzo realizado ${ }^{55}$. Su esperanza es poder asirse a la definitiva Ley de Memoria Histórica que se tramita en el parlamento español en la actualidad, del que se derivará alǵunas exigencias a las CCAA que no han implementado normativa alguna para la RMH y la creación del necesario Instituto o Centro de la MHD. Este deberá coordinar e incentivar las actuaciones del asociacionismo memorialista regional y visibilizar sus logros creando «Itinerarios de la memoria» como se está haciendo en otras regiones españolas ${ }^{56}$. Por poner un ejemplo, en casi todas las provincias de $\mathrm{CyL}$ se han levantado panteones y memoriales con placas alusivas a la lucha por las libertades democráticas de las víctimas o se han erigido «Hitos de la memoria» para recordar «Lugares de la memoria» como son las fosas comunes o los lugares de los asesinatos. En la mayoría de las capitales de las provincias existe un Memorial levantado en honor a todas las víctimas de la provincia y en muchos de los principales pueblos que sufrieron especial virulencia. Con ellos se podrían realizar itinerarios de la represión franquista en todas y cada una de las provincias, como lugares de la memoria que son hoy patrimonio material e inmaterial que constituyen el basamento de nuestra democracia. La señalización de todos ellos con balizas o hitos escultóricos alusivos, como ya tienen algunas, es una obligación de la democracia actual, al igual que la revisión de los libros de texto con la incorporación de la MD, como se ha señalado. Estas son hoy las principales preocupaciones del asociacionismo regional, después de tan larǵa experiencia acumulada.

55 Son tantos los nombres de los voluntarios/as que han formado parte de los equipos directivos del memorialismo regional, que no es posible hacer una lista sin olvidar a alguno/a. Debe pensar el lector en las 20 asociaciones trabajando durante 20 años en la recuperación de la $\mathrm{MH}$, con la realización de cientos de actos públicos, algunos de forma periódica en fechas señaladas del año, para darse cuenta del volumen de su actividad. Sin duda, algún día, alguien se atreverá a valorar el impacto social, cultural y político de sus actividades en el conocimiento y la formación de nuestra conciencia histórica.

${ }^{56}$ García Colmenares, 2021a y 2021b. 


\section{Bibliografía}

AA.VV., «La represión franquista en Castilla y León», número especial, Memòria antifranquista del Baix Llobregat, 13, 18, 2018.

Aguilar, Paloma, «Memoria y transición en España. Exhumaciones de fusilados republicanos y homenajes en su honor», Historia y Política, 39, 2018, pp. 291-325.

Barahona, Alexandra, Paloma Aguilar, y Carmen González (eds.), Las políticas hacia el pasado. Juicios, depuraciones, perdón y olvido en las nuevas democracias, Madrid, Itsmo, 2002.

Barranquero, Encarnación, y Lucía Prieto, La derrota bajo tierra. Las fosas comunes del franquismo, Granada, Comares, 2018.

Berzal, Enrique (coord.), Testimonio de voces olvidadas, León, Fundación 27 de Marzo, 2007, 2 vols.

Berzal, Enrique, «Una zona no tan "azul”. Guerra civil y represión en Castilla y León», en Juan Andrés Blanco et al., Luces sobre un pasado deformado. La Guerra Civil ochenta años después, Madrid, Marcial Pons, 2020, pp. 409-436.

Blanco, Juan Andrés, «Los estudios sobre la Guerra Civil en Castilla y León», Studia Zamorensia, 2, 1995, pp. 125-141.

Castro, Luis, Héroes y caídos. Políticas de la memoria en la España contemporánea, Madrid, Libros de la Catarata, 2008.

Cuesta, Raimundo, Los deberes de la memoria en la educación, Madrid, Octaedro, 2007.

Cuesta, Raimundo, «Historia con memoria y didáctica crítica», Con-Ciencia Social, 15 (monográfico), 2011, pp. 15-30.

Delgado, Severiano, y Santiago López, «Una aproximación a la Guerra Civil en Castilla y León», en Manuel Redero y Mª Dolores de la Calle (eds.), Castilla y León en la historia contemporánea, Salamanca, Universidad de Salamanca, 2008, pp. 427-486.

Díez Gutiérrez, Enrique y Rodríguez González, Javier, Unidades didácticas para la Recuperación de la Memoria Histórica, León, Foro por la Memoria y Ministerio de la Presidencia, 2009.

Díez Gutiérrez, Enrique, La asignatura pendiente. La memoria histórica democrática en los libros de texto escolares, Madrid, Plaza y Valdés Editores, 2020.

Eiroa San Francisco, Matilde, «¿Qué historia y qué memorias?: el pasado en la sociedad digital», en Matilde Eiroa San Francisco (coord.), Historia y Memoria en Red. Un nuevo reto para la historiografía, Madrid, Síntesis, pp. 67-91.

Etxeberria, Francisco, «Exhumaciones contemporáneas en España: las fosas comunes de la Guerra Civil», Boletín Galego de Medicina Legal Forense, 18, 2012, pp. 13-28.

Etxeberria, Francisco, «Las fosas comunes en el resurgir de la memoria en Castilla y León», Memòria antifranquista del Baix Llobregat, número especial, «La represión franquista en Castilla y León», 13, 18, 2018, pp. 14-22.

Etxeberria, Francisco, y Queralt Solé, «Fosas comunes de la Guerra Civil en el siǵlo XXI: antecedentes, interdisciplinariedad y legislación», Historia Contemporánea, 60, 2019, pp. 401-438. 
Fernández de Mata, Iǵnacio, Lloros vueltos puños. El conflicto de los «desaparecidos»y vencidos de la Guerra Civil española, Granada, Comares, 2016.

Fouce, Guillermo, «Lucha por los Derechos Humanos y la Justicia histórica en la España del siglo XXI», Hispania Nova. Revista de Historia Contemporánea, 7, 2007, s. p.

García Colmenares, Pablo, «Los usos públicos de la Historia: La memoria de la represión de la Guerra Givil en Palencia (1936-1939)», Revista de la Institución TTM, 76, 2005, pp. 121-239.

García Colmenares, Pablo (coord.), Historia y memoria de la Guerra Civil y primer franquismo en Castilla y León, Valladolid, Universidad de Valladolid, 2007.

García Colmenares, Pablo, Represión en una villa castellana de la retaguardia franquista. Dueñas (1936-1945), Palencia, Mํ Presidencia, 2008.

García Colmenares, Pablo, «Guerra Civil y represión en Castilla y León (1936-1945). Una visión todavía incompleta», Alcores, 7, 2009, pp. 203-228.

García Colmenares, Pablo, Víctimas de la guerra civil en la provincia de Palencia (1936-1945), Palencia, Mº Presidencia, 2011.

García Colmenares, Pablo, «Pacto de silencio y olvido de la Memoria Histórica en la Transición», en Jesús Ángel Redondo Cardeñoso (ed.), La Transición en Castilla y León. Democracia, autonomía y CEE, Valladolid, Universidad de Valladolid, 2021a, pp. 199-226.

García Colmenares, Pablo, La Memoria Histórica en España. Del movimiento memorialista a la conciencia histórica, Valladolid, Universidad de Valladolid, 2021b.

García-Rubio, Almudena, ¿Dónde está mi padre? Búsqueda, exhumación e identificación de las víctimas de la Guerra Civil en La Carcavilla, Palencia, Aranzadi, 2019.

Herrasti, Lourdes, «Fosas exhumadas entre los años 2000 y el 2019», en Francisco Etxeberria (coord.), Las exhumaciones de la Guerra civil y la dictadura franquista, 2000-2019. Estado actual y recomendaciones de futuro, Madrid, $\mathrm{M}^{\circ}$ de la Presidencia, 2020, pp. 18-50.

Herrero Balsa, Gregorio, y Antonio Hernández García, La represión en Soria durante la guerra civil, Soria, 1982, 2 vols. (Reedición en 2010 por la Asociación «Recuerdo y Dignidad»).

Hristova-Dijkstra, Marije, Memoria, olvido y la apertura de fosas comunes de la guerra civil, 1978-1981 y 2000-2006, Laren, 2007, https://www.academia. edu/11939315/Memoria_olvido_y_la_apertura_de_fosas_comunes_de_la_guerra_civil_en_1978_1981_y_2000_2006

Mate, Reyes, Tratado de la injusticia, Barcelona, Anthropos, 2007a.

Mate, Reyes, «¿Existe una responsabilidad histórica?», en AA.VV., Responsabilidad histórica. Preguntas del nuevo al viejo mundo, Barcelona, Anthropos, 2007b, pp. 354-372.

Mate, Reyes, La piedra desechada, Madrid, Trotta, 2013.

Molpeceres, Antonio, «Conflictos: la memoria de los alumnos de la Guerra Civil a la transición», Íber. Didáctica de las Ciencia Sociales, Geografía e Historia, 69, 2011, pp. 21-28. 
Ovejero Bernal, Anastasio, Trauma y memoria en las víctimas del franquismo. Su transmisión a las siguientes generaciones, Barcelona, editado por el autor, 2020, https://www.anastasio.ovejero.net/

Prada, Julio, La España masacrada. La represión franquista de guerra y posguerra, Madrid, Alianza, 2010.

Silva, Emilio, y Santiago Macías, Las fosas de Franco, Madrid, Temas de Hoy, 2003.

Silva, Emilio, Agujeros en el silencio. Renglones de memoria contra la impunidad del franquismo (2000-2020), Madrid, Postmetrópolis Editorial, 2020.

Vinyes, Ricard, «La memoria como política pública», en AA.VV., Políticas públicas de la memoria. I coloquio Internacional Memorial Democràtic, Lleida, Milenio, 2009, pp. 23-39. 